\title{
Ideologia, Democracia e Comportamento Parlamentar: A Câmara dos Deputados $(1991-1998)^{*}$
}

Eduardo Leoni

\section{INTRODUÇÃO}

— reqüentemente, políticos, jornalistas, acadêmicos e cidadãos em

- geral utilizam conceitos espaciais para identificar as posições dos atores políticos. Dizemos, por exemplo, que certo candidato está mais à esquerda de um, porém mais à direita de outro. A teoria espacial do voto é uma formalização dessas idéias. Ela parte do pressuposto de que as preferências individuais e as políticas podem ser representadas como pontos em um espaço. Os atores dão primazia às políticas mais próximas em detrimento daquelas que estão mais distantes de seus pontos ideais.

\footnotetext{
* Este artigo é uma versão revisada de parte da minha dissertação de mestrado defendida junto ao Departamento de Relações Internacionais da Universidade de Brasília. Agradeço a Keith Poole por disponibilizar na Internet o programa estatístico de sua autoria (com Howard Rosenthal) utilizado aqui (http:/ / voteview.uh.edu), e a Fernando Limongi e Argelina Figueiredo por terem dado acesso à base de dados CEBRAP - Votações Nominais na Câmara dos Deputados. Os membros da minha banca, Maria Helena de Castro Santos, Bernardo Mueller e Maria Izabel Valladão de Carvalho forneceram valiosos comentários que melhoraram muito o texto. Agradeço ainda a Lucio Rennó e a Carlos Pereira pelas trocas incessantes de e-mails, dados e opiniões neste e em outros trabalhos. Qualquer disparate que tenha permanecido no texto é de minha inteira responsabilidade.
}

DADOS - Revista de Ciências Sociais, Rio de Janeiro, Vol. 45, nº 3, 2002, pp. 361 a 386. 
O número de dimensões corresponde ao número de áreas temáticas relevantes para os atores. Por exemplo, cada indivíduo pode ter avaliações distintas em questões de finanças públicas, comércio exterior, política antidrogas etc., por isso, a dimensionalidade do espaço político pode ser muito alta.

Um dos objetivos deste artigo é responder à pergunta: quantas dimensões são necessárias para representar adequadamente as preferências dos legisladores da Câmara dos Deputados brasileira no período 1991-1998? Para respondê-la, será necessária uma rápida introdução à teoria espacial do voto. Em seguida, apresentaremos o método estatístico W-NOMINATE que, a partir das votações dos deputados, infere as localizações espaciais destes em uma ou mais dimensões.

Veremos que, de fato, uma dimensão explica a maior parte das votações na Câmara dos Deputados, pois dimensões adicionais não melhoram significativamente a capacidade explicativa do modelo estatístico. Falar em centro, direita e esquerda parece, afinal, fazer sentido no caso brasileiro. Sugerimos que, no período estudado, os "governistas" ocupam um extremo e a "oposição", o outro, estando os deputados distribuídos ao longo desse continuum ideológico. Ideologia tem um significado específico aqui: o de constranger os atores a expressar suas preferências em um espaço de baixa dimensão.

\section{TEORIA ESPACIAL DO VOTO}

Vamos supor que a Comissão de Finanças e Tributação da Câmara dos Deputados tenha que decidir qual a taxa de imposto de renda para pessoas físicas no Brasil. Vamos supor ainda que o conjunto de alternativas possíveis vá de $0 \%$ a 100\%. Os seguintes partidos, em vez dos deputados, fazem parte da comissão: PT, PDT, PSDB, PMDB e PFL. Isto é, estamos supondo que os partidos são atores unitários. A preferência de cada um deles pode ser representada por um ponto na linha que vai de 0 a 100 .

Assumimos que as preferências têm pico único, ou seja, têm seu valor máximo no ponto ideal de cada indivíduo (partido), decrescendo monotonicamente para ambos os lados.

Uma das funções que apresenta essas propriedades é a que possui forma de tenda, como a que observamos na Figura 1. Assumimos 
Figura 1

Exemplo: Localização dos Pontos Ideais dos Partidos

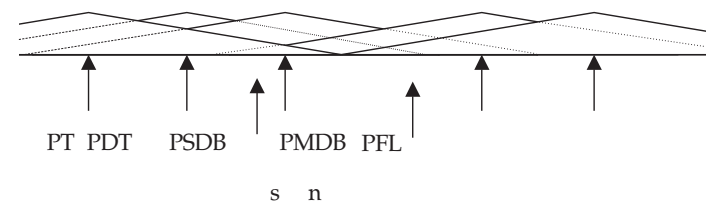

também que todos votam. Assim, dadas duas alternativas s e $n$, o partido $k$ vota em $s$ se e somente se:

$$
|\mathrm{s}-\mathrm{k}|<|\mathrm{n}-\mathrm{k}|
$$

Isto é, se $s$ está mais próxima de $k$ do que $n$, o voto do indivíduo (no caso, partido) $k$ vai para $s$. Do contrário, vai para $n$. Para exemplificar, vamos supor que o status quo esteja em $n$. Em uma votação hipotética existe uma proposta $s$ que muda a política do ponto $n$ para o ponto $s$. Quem vota a favor de $s$ ? É fácil observar que o PMDB e o PFL estão mais próximos do status quo $n$ do que de $s$, e portanto votam "Não". PT, PDT e PSDB, por outro lado, estão mais perto de $s$, votando "Sim". Se assumirmos que cada partido dispõe de apenas um voto, a proposta passa e o resultado é uma mudança da política do ponto $n$ para o pontos.

O teorema de Black (1958) estabelece que, em contextos unidimensionais com preferências de pico único, existe um equilíbrio bem definido: a posição mediana. Na Figura 1, a posição mediana corresponde à do PSDB. Se o status quo está localizado no ponto ideal do PSDB, e o PFL sugere $n$ ou qualquer ponto à direita do PSDB, o PT, o PDT e o próprio PSDB votarão contra e a posição mediana vence. Se o PDT, por sua vez, sugere $s$ ou qualquer outro ponto à esquerda do PSDB, $\mathrm{o}$ PFL, o PMDB e o PSDB votarão contra, permanecendo a política em PSDB. Ou seja, a posição mediana nunca perde em uma decisão pela regra da maioria.

Observe que precisamos conhecer tanto a localização da proposta como a do status quo para podermos predizer os votos. Em livro recente, Ames ignora este fato e se pergunta:

"Se a maior parte dos projetos de legislação tem por objetivo satisfazer o legislador mediano, os membros conservadores dos partidos de 
direita seriam os mais insatisfeitos e, portanto, mais inclinados à indisciplina [...] Por que os conservadores cooperam?" (2001:221, tradução nossa)

Para esse autor, a resposta são pagamentos colaterais para que os deputados deixem suas ideologias de lado. No entanto, ao representarmos cada votação como dois pontos no espaço, os achados de Ames tornam-se consistentes com o modelo espacial.

Retornemos à ordem dos partidos exposta na Figura 1, supondo agora que o status quo esteja à esquerda do PDT. Em uma votação entre esse status quo e a posição mediana (PSDB), o PFL (o membro mais conservador) vota em favor da posição mediana. Afinal, sendo $x_{i}$ o ponto ideal do partido $i$ (ou do status quo), $\left|x_{P F L}-x_{P S D B}\right|<\left|x_{P F L}-x_{\text {status quos }}\right|$. Portanto, não há uma coalizão dos extremos contra a mediana como Ames faz supor.

Outra questão é o que acontece quando mais de uma dimensão é relevante. Considere um plano em que há uma dimensão social e outra econômica. Indivíduos e políticas podem ser localizados em qualquer lugar desse plano. A teoria da escolha social informa-nos que, nessas condições, tudo pode acontecer. Isto é, o caos instaura-se (McKelvey, 1976). Daí a importância teórica da dimensionalidade do espaço político.

Por último, em votações nominais, partidos não votam, mas sim os deputados individualmente. Temos que estar atentos à possibilidade de os deputados estarem localizados mais à esquerda ou mais à direita dentro dos seus respectivos partidos.

\section{ANÁLISE ESPACIAL DAS VOTAÇÕES NOMINAIS}

Até agora, a discussão baseou-se na seguinte premissa: sabemos quais são as posições das políticas e dos representantes. O problema, obviamente, é como identificar as posições das 235.831 decisões e dos 963 legisladores na Câmara dos Deputados ${ }^{1}$ no período que se estende de 1991 a 1998.

Limongi e Figueiredo argumentam que com a simples tabulação das proporções em que os líderes dos maiores partidos apresentaram encaminhamentos similares (Tabela 1), podemos perceber uma estrutura nos dados. 
“Os partidos aqui são apresentados de acordo com a ordenação ideológica sugerida pela própria análise dos dados. A Tabela 1 apresenta de maneira (clara) a prevalência do ordenamento proposto [...]. A disposição dos partidos no continuum ideológico direita-esquerda emerge de maneira nítida [...]. A distância entre os dois extremos é patente: a concordância entre os líderes do PDS e do PT ocorreu em apenas $13,6 \%$ dos casos. Observe-se ainda que o centro está bem mais próximo da direita que da esquerda." (Limongi e Figueiredo, 1995:502, ênfases nossas)

Tabela 1

Proporção de Encaminhamentos Similares pelos Líderes de cada Partido

\begin{tabular}{l|cccccc}
\hline Partidos & PFL & PTB & PMDB & PSDB & PDT & PT \\
\hline PDS & 68,8 & 61,5 & 54,8 & 43,4 & 20,4 & 13,6 \\
PFL & & 64,3 & 64,3 & 46,6 & 17,2 & 11,8 \\
PTB & & & 55,2 & 45,7 & 22,2 & 15,8 \\
PMDB & & & & 64,3 & 37,6 & 30,3 \\
PSDB & & & & & 49,3 & 48,9 \\
PDT & & & & & & 71,5 \\
\hline
\end{tabular}

Reproduzida de Limongi e Figueiredo (1995, Tabela 1).

A proporção dos votos em que os líderes dos partidos concordam (índice de concordância) tem conotação espacial. Isto é, partidos podem estar mais ou menos distantes uns dos outros, estando mais próximos quanto mais votarem juntos. Note que a estrutura ideológica sugerida pelos autores é constituída por uma só dimensão (esquerda-centro-direita), mas não são apresentadas evidências para fundamentar tal hipótese.

Como os partidos no Brasil não são totalmente coesos, o ideal seria estimar as preferências de cada deputado, e não somente dos líderes ou dos agregados partidários. O problema é bastante complexo. Temos que identificar em cada legislatura as posições de cerca de 500 deputados, observando um quadro com 124.750 distâncias. Seria como tentar desenhar o mapa de uma região desconhecida a partir de um quadro contendo apenas as distâncias entre os municípios. E mais, não se sabe ainda se as distâncias incluem ou não as altitudes!

Felizmente, existe um conjunto de técnicas estatísticas específicas para resolver esse tipo de problema: métodos de escalonamento mul- 
tidimensional. Note que não cabe ao analista determinar a priori quantas dimensões são necessárias, nem qual o conteúdo substantivo destas. Este trabalho é feito a posteriori por diferentes métodos: análise das medidas de ajuste estatístico, análise dos gráficos (mapas), regressões lineares etc.

\section{O Procedimento NOMINATE}

Métodos de escalonamento multidimensional não têm como base a teoria espacial do voto. Por isso, Poole e Rosenthal desenvolveram o procedimento NOMINATE, acrônimo de Nominal Three-Step Estimation (Estimação Nominal em Três Passos), que expomos brevemente a seguir e que utilizaremos no decorrer deste artigo.

Escolhemos esse método pelas seguintes razões: a) as estimativas resultantes são o atual padrão na ciência política norte-americana, o que permite a comparação imediata dos resultados obtidos aqui com o de outras assembléias legislativas; b) é um dos métodos mais diretamente ligados à teoria espacial do voto; c) os programas e documentação necessários estão disponíveis na Internet.

O método possibilita a estimação de posições multidimensionais para as políticas e os legisladores. As coordenadas são forçadas a situar-se em uma hiperesfera de raio 1 centrada em zero (Poole e Rosenthal, 1997:234).

Precisamos, primeiro, de alguma notação: $s$ representa o número de dimensões indexadas por $k=1 \ldots s ; p$ representa o número de legisladores $(i=1, \ldots, p) ; q$, o número de votações $(j=1, \ldots, q)$. O ponto ideal do legislador $i$ é $x_{1}=\left(x_{i 1}, x_{i 2}, \ldots, x_{i s}\right)$. Cada votação é representada por $z_{\mathrm{jy}} \mathrm{e}$ $\mathrm{z}_{\mathrm{jn}}$, onde y e n são as conseqüências políticas dos resultados "Sim" e "Não", respectivamente.

A utilidade para o legislador na votação $j$ é dada por:

$$
\left.U_{i j y}=\beta \exp \left(-\sum_{k=1}^{s}\left(x_{i k}-z_{j y k}\right)^{2}\right)\right)+\varepsilon_{i j y}
$$

A soma representa a distância euclidiana entre a política "Sim" e o ponto ideal do legislador. $\beta$ é uma constante que indica a razão de sinal para barulho, comum a todos os legisladores. $O$ termo $\varepsilon$ segue a distribuição logística. 
O problema, nada trivial, é achar $\beta$, os $x, z_{j y k}$ e $z_{j n k}$ que maximizam a verossimilhança. É semelhante a inferir os betas e os $x$ em uma regressão logística em que só dispomos da variável dependente. A solução encontrada por Poole e Rosenthal para esse problema foi um dos maiores avanços da ciência política quantitativa ${ }^{2}$.

\section{Dimensionalidade e Precisão do Modelo no Caso Brasileiro}

Equilíbrios em contextos multidimensionais induzidos unicamente pelas preferências dos atores são (teoricamente) raros a ponto de serem implausíveis. Se o espaço em que os políticos fazem suas escolhas são de fato multidimensionais, esperaríamos que as decisões no Legislativo fossem caóticas. Um modelo que tentasse explicar essas decisões seria certamente muito complexo.

No entanto, a existência ou não de caos, assim como o número de dimensões relevantes, são questões empíricas. Quanto das decisões individuais dos deputados é explicado por um modelo simples, com uma ou duas dimensões? A adição de mais dimensões melhora significativamente o poder explicativo do modelo?

Os dados utilizados neste artigo são provenientes do Banco de Dados Legislativos CEBRAP - Votações Nominais na Câmara dos Deputados - 1988-1999, coordenado por Fernando Limongi e Argelina Cheibub Figueiredo. Nele são registradas todas as votações nominais na Câmara dos Deputados de novembro de 1989 a fevereiro de 1999. Analisamos aqui as votações da 49aㅡ e da 50를 legislaturas (1991-1999).

O programa W-NOMINATE inclui na análise somente os deputados que votaram pelo menos 25 vezes em cada período em estudo. Todas as votações em que o lado minoritário excedeu 2,5\% dos votos foram incluídas. Apesar de excluir algumas votações não unânimes, esse corte é bem menor que o utilizado nos trabalhos de Limongi e Figueiredo $(10 \%)$, por exemplo.

O Banco de Dados do CEBRAP também inclui a identificação partidária dos deputados a cada votação. Adotamos, no entanto, "retratos" da identificação: a) o partido em que o deputado estava quando votou pela primeira vez na legislatura em questão; b) o partido do deputado na primeira vez que votou quando Itamar Franco substituiu Fernando Collor na Presidência da República no decorrer da 49a legislatura; c) o último partido do deputado na $50^{\underline{a}}$ legislatura. Quando o texto 
Tabela 2

Deputados e Votações Nominais Incluídos na Análise, por Legislatura

\begin{tabular}{l|cccc}
\hline Legislatura & $\begin{array}{c}\text { Deputados } \\
\text { Votantes }\end{array}$ & $\begin{array}{c}\text { Deputados } \\
\text { Incluídos }\end{array}$ & $\begin{array}{c}\text { Votações No- } \\
\text { minais }\end{array}$ & $\begin{array}{c}\text { Votações } \\
\text { Nominais Incluídas }\end{array}$ \\
\hline $49^{\text {a }}$ & 620 & 569 & 166 & 164 \\
$50^{\text {a }}$ & 635 & 615 & 449 & 452 \\
\hline
\end{tabular}

Fonte: Cálculos do autor a partir da base de dados CEBRAP.

não indicar o contrário, as filiações partidárias são as do último período disponível em cada legislatura.

Foram incluídos na análise, além dos deputados, os líderes partidários, por meio de suas indicações (ou "encaminhamentos") ao plenário. O PDS, o PPR e o PPB são tratados como um só partido. Os presidentes da República o são como membros da Câmara, isto é, as indicações do líder do governo ${ }^{3}$ entram na análise como se fossem ações de um "legislador".

A estrutura das votações nominais na Câmara do Deputados é claramente unidimensional, afinal, com apenas uma dimensão, o procedimento W-NOMINATE classifica corretamente $86,4 \%$ (49a legislatura) e $90,4 \%$ (50a) das votações nominais (Tabela 3 ).

Essa medida, no entanto, tende a superestimar a capacidade preditiva do modelo, especialmente quando existem muitos votos em que a maioria supera em larga escala a minoria. Vamos supor que, em determinada votação, em uma assembléia com 100 representantes, 80 votaram "Sim" e 20, "Não". Sem nenhum modelo matemático ou sabedoria política, um observador poderia fazer a predição de que todos votaram igual e acertar $80 \%$ dos votos (errando $20 \%$ ). Parece claro que, para um modelo qualquer ter realmente alguma capacidade explicativa, ele terá que acertar mais do que essa predição ingênua.

Por isso, criou-se uma medida chamada redução proporcional do erro, ou PRE. Ela é definida como \% erros ingênuos - \% erros com o modelo/\% erros ingênuos. No caso:

PRE $=\frac{\text { Votos da Minoria }- \text { Erros feitos pelo NOMINATE }}{\text { Votos da Minoria }}$ 
Se, no exemplo anterior, o modelo acerta $90 \%$ dos casos (ou seja, erra $10 \%)$, o PRE será de $(20 \%-10 \%) / 20 \%=50 \%$. Ou seja, o modelo reduz os erros em $50 \%$.

APRE, por sua vez, é a redução proporcional do erro agregado, e é definida como:

$$
\text { APRE }=\sum_{j=1}^{n} \frac{\text { Votos da Minoria }_{j}-{\text { Erros feitos pelo } \text { NOMINATE }_{j}}_{j=1}^{n} \text { Votos da Minoria }_{j}}{\sum_{j}}
$$

Tabela 3

Classificação Correta e Redução Proporcional do Erro Agregado (APRE), $49^{\text {a }}$ e $50^{\text {a }}$ Legislaturas

\begin{tabular}{c|cc|cc}
\hline Dimensões & $\begin{array}{c}\text { Classificados } \\
49^{\mathrm{a}}(\%)\end{array}$ & $\begin{array}{c}\text { APRE } \\
49^{\mathrm{a}}(\%)\end{array}$ & $\begin{array}{c}\text { Classificados } \\
50^{\mathrm{a}}(\%)\end{array}$ & $\begin{array}{c}\text { APRE } \\
50^{\mathrm{a}}(\%)\end{array}$ \\
\hline $\mathbf{1}$ & 86,4 & 52,3 & 90,4 & 64,8 \\
$\mathbf{2}$ & 88,6 & 60,2 & 91,2 & 67,8 \\
$\mathbf{3}$ & 89,8 & 64,4 & 92,0 & 70,5 \\
$\mathbf{4}$ & 90,5 & 66,8 & 92,5 & 72,3 \\
$\mathbf{5}$ & 91,0 & 68,5 & 92,7 & 73,4 \\
$\mathbf{6}$ & 91,6 & 70,6 & 93,0 & 74,3 \\
$\mathbf{7}$ & 92,1 & 72,2 & 93,2 & 75,1 \\
$\mathbf{8}$ & 92,5 & 73,7 & 93,4 & 75,8 \\
$\mathbf{9}$ & 92,8 & 74,9 & 93,6 & 76,5 \\
$\mathbf{1 0}$ & 93,1 & 76,0 & 93,7 & 77,0 \\
$\mathbf{1 1}$ & 93,4 & 76,9 & 93,9 & 77,5 \\
$\mathbf{1 2}$ & 93,4 & 76,9 & 93,9 & 77,5 \\
$\mathbf{1 3}$ & 93,4 & 76,9 & 94,0 & 77,9 \\
$\mathbf{1 4}$ & 93,4 & 76,9 & 94,1 & 78,4 \\
$\mathbf{1 5}$ & 93,4 & 76,9 & 94,1 & 78,4 \\
\hline
\end{tabular}

Fonte: Cálculos do autor a partir da base de dados CEBRAP.

Os valores de APRE e de classificação correta de uma a quinze dimensões estão na Tabela 3. Essas medidas possibilitam a utilização de um dos critérios para a escolha da dimensionalidade do modelo. O Gráfico 1 mostra quanto de explicação adicional em termos de classificação correta cada dimensão traz. Observe que a segunda dimensão adiciona pouco mais de $2 \%$ na $49^{\text {a }}$ legislatura. Quando adicionamos uma 
Gráfico 1

Ganho na Classificação por Dimensão Adicional

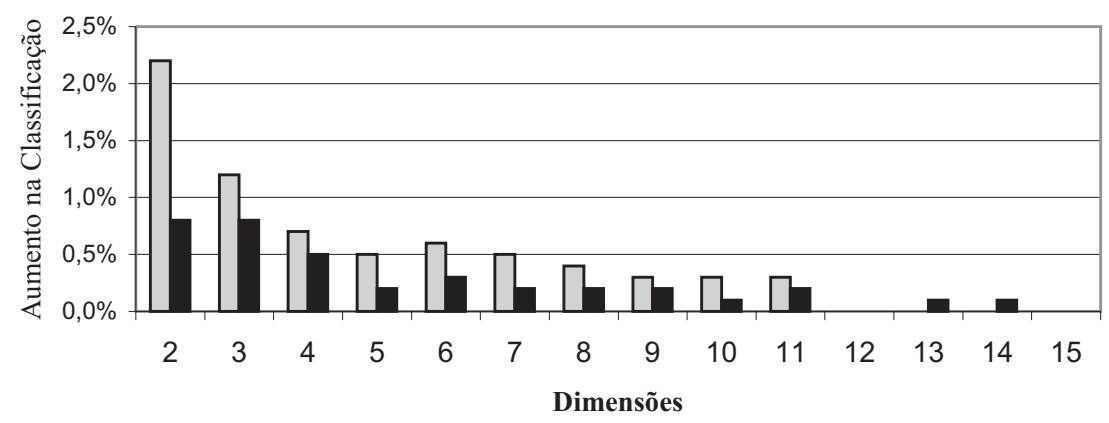

49a. Legislatura $\square$ 50a. Legislatura

terceira dimensão, mais 1,2\% dos votos é corretamente classificado. A partir daí, cada dimensão adicional acrescenta menos de $1 \%$ de explicação.

Uma maneira de se estimar a dimensionalidade consiste em observar quando os dados fazem um "cotovelo", ou seja, uma queda acentuada na explicação adicional. Em dois momentos, verifica-se essa queda na $49^{\underline{a}}$ legislatura: da $1^{\underline{a}}$ para a $2^{\underline{a}}$ dimensão (de $86 \%$ para $2 \%$ ), e da $2^{2}$ para a $3^{\text {a }}$ (de $2 \%$ para $\left.1 \%\right)$.

Na $50^{\underline{a}}$ legislatura, no entanto, tanto a $2^{\underline{a}}$ como a $3^{\underline{a}}$ dimensões adicionam menos de $1 \%$ na explicação. Não há nenhum critério em termos de ajuste estatístico para escolhermos entre um modelo bi ou tridimensional. Podemos dizer que a 50를 Legislatura é essencialmente unidimensional.

Só saberemos se $90 \%$ de predição correta ou $60 \%$ de APRE são números de monta se analisarmos os dados comparativamente. A Tabela 4 apresenta os resultados do Parlamento Europeu, da Casa dos Representantes americana, da Assembléia Nacional Francesa e da Câmara dos Deputados brasileira em uma e duas dimensões.

Mesmo com deputados orientados (segundo parte significativa da literatura) por políticas distributivas, e com partidos políticos fracos e sem vínculos com a sociedade, a Câmara dos Deputados brasileira 
Tabela 4

Resultados W-NOMINATE para a Câmara dos Deputados e outros Legislativos

\begin{tabular}{l|ccc}
\hline Legislativo & Dimensões & $\begin{array}{c}\text { Classificados } \\
\text { Corretamente } \\
(\%)\end{array}$ & $\begin{array}{c}\text { APRE } \\
(\%)\end{array}$ \\
\hline 105 $^{\text {a }}$ Casa dos Representantes americana & Uma & 88,2 & 64,4 \\
$(1997-98)^{*}$ & Duas & 89,2 & 67,4 \\
$4^{\circ}$ Parlamento Europeu (1995-97)* & Uma & 89,4 & 53,6 \\
& Duas & 91,4 & 62,2 \\
Parlamento Britânico (1841)* & Uma & 89,7 & 65,1 \\
& Duas & 92,5 & 74,8 \\
Assembléia Nacional Francesa (1951-56)* & Uma & 93,3 & 81,8 \\
& Duas & 96,0 & 89,2 \\
Câmara dos Deputados brasileira na 49a & Uma & 86,4 & 52,3 \\
Legislatura (1991-95)** & Duas & 88,6 & 60,2 \\
Câmara dos Deputados brasileira na 50 & Uma & 90,4 & 64,8 \\
Legislatura (1995-98)** & Duas & 91,2 & 67,8 \\
\hline
\end{tabular}

Fontes: * Poole e Rosenthal (2001, Tabela 4); ** Tabela 3 deste artigo.

encaixa-se no modelo espacial tão bem como o legislativo nacional norte-americano, ou como legislativos de países europeus famosos pela disciplina partidária.

\section{POSIÇÕES IDEOLÓGICAS DOS DEPUTADOS: 49aㅡ E 50ª LEGISLATURAS}

O procedimento NOMINATE foi criado para testar a hipótese das injunções ideológicas. Apesar de o espaço político ter potencialmente uma dimensionalidade muito alta, as injunções ideológicas fariam o espaço efetivo (com base em que as decisões são feitas) ter um número bem pequeno de dimensões. Os procedimentos que existiam antes, argumentam Poole e Rosenthal (1985:358-360), superestimavam o número de dimensões, sendo inapropriados para o teste de modelos espaciais.

A discussão sobre dimensionalidade da seção anterior não pode obscurecer o achado mais importante: a quase unidimensionalidade da estrutura das votações nominais na Câmara dos Deputados. Por que não achamos, como seria de se esperar dada a complexidade das 
questões tratadas na Câmara, caos ou uma multidimensionalidade mais acentuada?

Analogias espaciais da política, como "esquerda", "centro" e "direita", tendem a ser unidimensionais. São representações abstratas, mas legisladores e eleitores parecem utilizar esses conceitos como auxílio em suas decisões políticas. Nos Estados Unidos, por exemplo:

\begin{abstract}
“Um liberal dos dias de hoje [...] provavelmente apóia um aumento no salário mínimo; [...] é contra o uso de força no estrangeiro; apóia programas compulsórios de ação afirmativa; e apóia o financiamento federal de programas seguro-saúde e creches. De fato, saber se um político se opõe a um aumento no salário mínimo é suficiente para predizer, com razoável confiabilidade, a opinião do político em muitas questões aparentemente desconexas" (Poole e Rosenthal, 1997:11, tradução nossa).
\end{abstract}

A capacidade de predizer o posicionamento de um deputado em uma variedade de questões aparentemente não relacionadas revela a presença de injunções ideológicas. Poderíamos até afirmar que não existem diversas dimensões políticas (segurança nacional, direitos civis, impostos, salário mínimo etc.), mas apenas uma: ideologia, variando da esquerda a moderados, à direita.

O que esquerda e direita significam depende do contexto histórico e cultural. É necessário que essa acepção seja compartilhada por grande parte dos atores, e que seja possível ser mais ou menos "de esquerda" ou "de direita". Além disso, as dimensões do espaço ideológico não são fixas, mas latentes, ou seja, elas são determinadas pela maneira como estão relacionadas às crenças ou retórica dos políticos (Hinich e Munger, 1997:191). O W-NOMINATE é um método que se propõe a recuperar as dimensões em que as decisões políticas são tomadas por meio da análise das votações nominais.

O espaço ideológico não está divorciado das questões políticas. As $n$ dimensões políticas são "mapeadas" no espaço ideológico de baixa dimensionalidade, mas ainda não existem teorias explicando esse processo. Para tentar, pelo menos, descrever o que acontece, temos que interpretar a estrutura das votações nominais. Afinal, qual o conteúdo substantivo das dimensões? 
É claro que pode haver mais de uma dimensão ideológica. No caso norte-americano, Poole e Rosenthal (1997:47) consideram que, em alguns períodos, uma segunda dimensão é, de fato, necessária, conseqüência da distinção entre questões raciais e econômicas. Nos congressos recentes, no entanto, as questões de raça vêm se tornando cada vez mais questões redistributivas (econômicas).

Voltando ao caso brasileiro, nosso primeiro objetivo é analisar o quadro partidário e suas modificações no período, à luz da representação espacial dos pontos ideais dos deputados. Antes de tudo, porém, um aviso. Como os dados não são rodados todos juntos (a análise é feita por legislatura), o procedimento não constrange a posição dos deputados a manter-se a mesma nas duas legislaturas. Como as distâncias reveladas são relativas à posição dos outros deputados, não podemos saber se o movimento do deputado $A$ de 0,2 para 0,8 significa uma mudança na composição da Câmara ou um efetivo movimento à direita do deputado. Este fato deve ser especialmente considerado no Brasil, onde a renovação quase sempre excede os $50 \%$. Comparações entre as posições relativas dos deputados ou partidos podem ser feitas sem problemas.

Como seria a representação espacial de um modelo partidário do tipo Westminster, ou seja, com dois partidos altamente disciplinados? Ora, se os deputados de cada partido realmente votassem sempre juntos, veríamos dois pontos no espaço, onde os deputados estariam concentrados. Se há, vez por outra, alguma "rebeldia", seriam dois grupos separados de pontos bem concentrados. De qualquer forma, a análise espacial de um Legislativo desse tipo seria quase desprovida de interesse. As decisões de interesse, na verdade, já teriam sido tomadas antes, pelos comitês partidários e/ou pelos líderes.

Quando os partidos não são coesos, os pontos ideais dos deputados tendem a estar mais dispersos no espaço e a dimensionalidade passa a ser uma questão empírica. Já vimos que, na Câmara dos Deputados brasileira, uma ou duas dimensões são suficientes para explicar os votos dos deputados. A seguir estão representados os pontos ideais dos deputados graficamente.

Na 49aㅡ legislatura (Figura 3), a 1를 dimensão reflete o espectro esquerda-direita que os observadores da política brasileira têm em mente para o período: PT-PDT-PSDB-PMDB-PFL-PPB-PTB. Os três partidos 
Figura 2

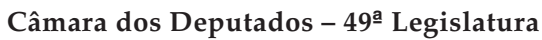

Pontos Ideais dos Deputados
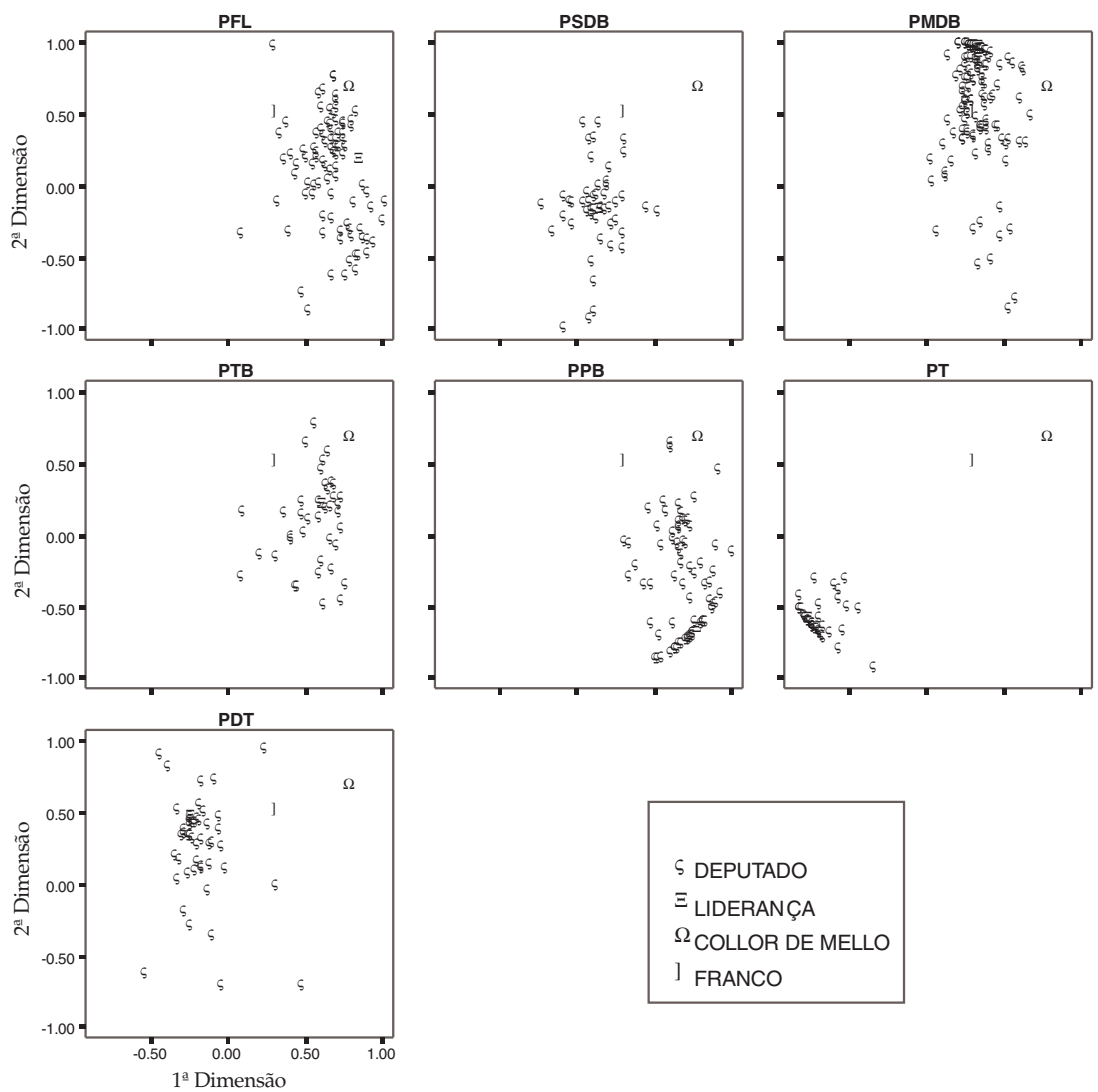

da direita não se distinguem bem na primeira dimensão e PTB e PFL são separados pela $2^{a}$ dimensão (a dimensão vertical). $\mathrm{O}$ PPB, por sua vez, não ocupa uma posição distinta da dos outros partidos da direita. O PSDB é nitidamente um partido de centro-esquerda, mas a sua diferença com o PMDB se deve mais à $2^{a}$ dimensão. O PT e o PDT diferenciam-se tanto na $1^{\underline{a}}$ quanto na $2^{2}$ dimensão. O PSDB e o PMDB, por sua vez, distinguem-se melhor pela $2^{\underline{a}}$ dimensão.

Os líderes partidários, de modo geral, não estão separados dos respectivos partidos. A exceção é o líder do PFL. Aparentemente, ele se comportou como os mais extremados dos seus membros. O PTB, por sua vez, ocupa posições aleatórias à direita na primeira dimensão. 
Figura 3

Câmara dos Deputados - 50ํㅗㄹ Legislatura

Pontos Ideais dos Deputados
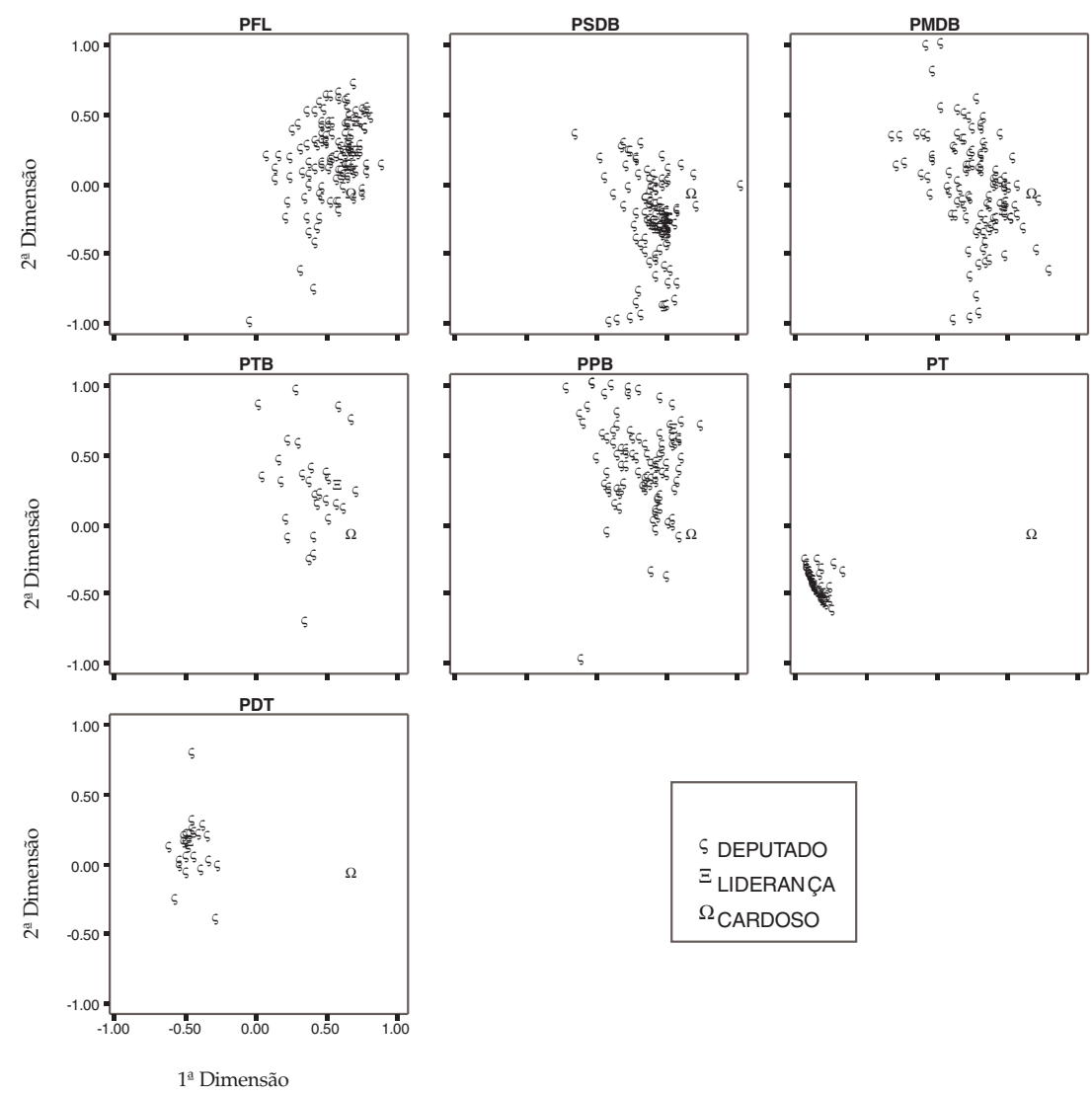

$\Xi$ LIDERANÇA

$\Omega$ CARDOSO

O presidente Fernando Collor de Mello está no extremo direito do espectro político. Somente $9 \%$ da Câmara tem pontos ideais à direita do seu. O presidente Itamar Franco, por outro lado, ocupa uma posição central no espaço, e nada menos que $60 \%$ dos deputados estão à sua direita.

A $50^{a}$ legislatura é a que marca um grande número de mudanças no mapa espacial partidário. Em primeiro lugar, porque PTB, PMDB e PPB aparecem mais aleatoriamente dispersos no espaço à direita da $1^{\text {a }}$ dimensão. O PSDB, por sua vez, passou de um partido de centro ou centro-esquerda para um partido à direita na $1^{\underline{a}}$ dimensão. A $2^{\underline{a}}$ dimensão divide a coalizão de governo: PFL, PTB e PPB, de um lado, 
PMDB e PSDB, de outro. Essa dimensão separa também o PT do PDT. No entanto, é importante lembrar que a $2^{2}$ dimensão acrescenta menos de $1 \%$ à explicação.

O traço mais interessante é a fenda que se abre entre governo e oposição. Não há mais partidos de centro-esquerda, principalmente por causa da mudança de localização espacial do PSDB. A coalizão de governo (PFL, PPB, PMDB, PSDB e PTB) aparece quase toda à direita na $1^{a}$ dimensão. Ainda podemos distinguir visualmente os partidos, mas não tão bem quanto na $49^{a}$ legislatura. O presidente Fernando Henrique Cardoso, a exemplo de Collor, está bem à direita na $1^{\underline{a}}$ dimensão, com somente $7 \%$ do plenário à sua direita.

Quais as questões que "acionam" a segunda dimensão? Para responder a esta pergunta temos que definir que características das votações evidenciam divisões na $2^{\text {a }}$ dimensão. Poole e Rosenthal utilizam os seguintes critérios: a) selecionar as votações onde o PRE com duas dimensões é maior que $50 \%$, ou seja, em que o modelo bidimensional consegue explicar bem os votos; $b$ ) destas, selecionar aquelas em que a diferença entre o PRE com duas dimensões e o PRE com uma só dimensão seja maior que $10 \%$, ou seja, votações em que a $2^{\underline{a}}$ dimensão melhora consideravelmente a predição.

O Quadro 1 mostra quantas votações (e a porcentagem em relação ao total de votações no período) satisfazem esses critérios. Como não havia na base de dados do CEBRAP uma variável codificando as questões por áreas temáticas, foi necessário fazer nossa própria codificação.

Na 50a legislatura, não há um padrão definido sobre quais os tipos de questões são de segunda dimensão, pois existe uma grande variedade de questões, mas com poucas votações em cada. Das 452 votações somente 16 cumpriram os critérios.

Na 49aㅗ legislatura, no entanto, a $2^{\text {a }}$ dimensão ganha alguma consistência. Das 23 votações sobre legislação tributária, 10 tinham um componente considerável de segunda dimensão. Das 6 sobre dívidas dos estados e municípios, nada menos que 5 foram de segunda dimensão.

Para que a 2 a dimensão pudesse ser "acionada", os partidos deveriam encaminhar seus liderados de modo diferente do previsto pelo modelo espacial com uma só dimensão. De fato, das 21 votações da 49a le- 


\section{Quadro 1}

Assuntos das Votações em que a Redução Proporcional do Erro (PRE) Foi Maior que 50\% e em que a Diferença entre o PRE em Duas Dimensões e o PRE em uma Dimensão Foi Maior que 10\%

\begin{tabular}{|c|c|c|c|}
\hline Legislatura & $\begin{array}{c}\text { Votações } \\
\text { Selecionadas }\end{array}$ & $\begin{array}{c}\text { Total de } \\
\text { Votações }\end{array}$ & Assuntos ${ }^{*}$ \\
\hline $49^{\mathrm{a}}$ & $\begin{array}{c}21 \\
(13 \%)\end{array}$ & $\begin{array}{c}164 \\
(100 \%)\end{array}$ & $\begin{array}{l}10 \text { Legislação Tributária (23) } \\
5 \text { Dívidas dos Estados e Municípios (6) } \\
1 \text { Regimento Interno (1) } \\
2 \text { Administração Pública (9) } \\
1 \text { Previdência (3) } \\
1 \text { Legislação Eleitoral (9) } \\
1 \text { Empresa Nacional (1) }\end{array}$ \\
\hline $50^{\mathrm{a}}$ & $\begin{array}{c}16 \\
(4 \%)\end{array}$ & $\begin{array}{c}452 \\
(100 \%)\end{array}$ & $\begin{array}{l}2 \text { Regulação sobre Gás Natural (4) } \\
1 \text { Regulação Navegação de } \\
\text { Cabotagem (13) } \\
1 \text { Legislação Eleitoral (6) } \\
1 \text { Legislação Tributária (21) } \\
1 \text { Previdência (45) } \\
1 \text { Reeleição (8) } \\
9 \text { Outros }\end{array}$ \\
\hline
\end{tabular}

(*) Entre parênteses está o total de votações sobre o assunto no período.

gislatura, em 12 houve indicações contrárias ao modelo unidimensional (PPB e PT votando juntos contra o resto, por exemplo). Na 50a , entretanto, em apenas uma das 16 votações, os partidos indicaram em desacordo com o modelo unidimensional.

\section{Estabilidade das Dimensões}

Para serem fontes de coalizões estáveis, a $1^{\underline{a}}$ e a $2^{\underline{a}}$ dimensões devem não apenas ser importantes em um dado período legislativo, mas também entre períodos. As dimensões são estáveis através do tempo? Os deputados adotam uma só posição durante sua carreira, ou mudam muito de posição a cada eleição?

Em um país em que "realinhamentos" políticos ocorrem a cada eleição (Coppedge, 1998) - pelo menos 30\% dos deputados federais trocam de partido durante cada legislatura (Desposato, 1998:7) e pelo 
menos 50\% dos deputados não são reeleitos - se poderia esperar que a estabilidade das posições fosse baixa.

Podemos testar essa hipótese por meio de coeficientes de correlação linear. Se os deputados são estáveis no tempo, a correlação entre esse par de legislaturas deve ser alta. Se, por outro lado, os deputados mudam de idéia (ou posicionamento ideológico) a cada momento, as correlações devem ser baixas.

O índice de correlação entre essas legislaturas atingiu 0,80 , significativo no nível 1\% ( $\mathrm{N}=258)$. Este resultado é surpreendente. É verdade que, se comparados com seus análogos americanos (Poole, 1997), os resultados não são muito altos. No entanto, mesmo no pós-Guerra, a Casa dos Representantes teve alguns momentos em que a correlação entre Casas adjacentes no tempo foi mais baixa do que se demonstra aqui para o caso brasileiro, que, inclusive, tem mandatos mais longos (quatro anos versus dois, no caso americano). A $2^{2}$ dimensão não é nada estável. A correlação é de praticamente zero e sem significância estatística entre as duas legislaturas.

As decisões dos deputados, no entanto, não são feitas em um vácuo institucional, ou sem pressões dos diversos atores políticos. As preferências estimadas pelo procedimento NOMINATE são apenas uma aproximação das preferências dos deputados. Muitos dos efeitos de grupos de pressão ou da base eleitoral do deputado tendem a cancelar uns aos outros porque o procedimento usa quase todas as votações. Mas fatores sistemáticos, muitos deles institucionais, acabam por influenciar uma parte substancial das votações e, conseqüentemente, as estimativas das preferências.

Alguns fatores são constantes em uma determinada legislatura, mas variam de uma para outra. Se eles de fato influenciam as decisões individuais, sua variação pode ser responsável, no tempo, pela estabilidade espacial das preferências dos deputados.

Que fatores políticos podem ser a explicação para o padrão que encontramos nos resultados acima?

\section{Presidentes}

O Brasil no período estudado teve três presidentes: Fernando Collor de Mello e Itamar Franco na 49aㅗ e Fernando Henrique Cardoso na 
50․․ O problema de isolar a variável "presidente" de outros fatores está no fato de que não somente os presidentes variam, como também a composição do Legislativo. Isto impede, ou dificulta, separar os efeitos de cada uma dessas variáveis.

Por isso, a 49a legislatura pode proporcionar um interessante experimento natural. Das 164 votações do período que satisfizeram as condições para entrar na análise, 95 foram feitas enquanto o presidente era Collor de Mello e 69 no tempo de Itamar Franco. Realizamos separadamente o escalonamento dos dois períodos e analisamos a correlação entre ambos. Como base para comparação, fizemos também o escalonamento separado da $50^{\mathrm{a}}$ legislatura, dividindo-a entre a segunda e a terceira sessões legislativas.

Tabela 5

$1^{\text {a }}$ Dimensão W-NOMINATE - Correlações por Presidentes (49a) e Sessão Legislativa $\left(50^{\mathrm{a}}\right)^{*}$

\begin{tabular}{|c|c|c|c|c|}
\hline Sessão (T) & & $\mathrm{T}+1$ & $\mathrm{~T}+2$ & $\mathrm{~T}+3$ \\
\hline \multirow{3}{*}{$49^{\mathrm{a}}$ Collor } & & 2 anos & 4 anos & 6 anos \\
\hline & Pearson & 0,980 & 0,780 & 0,739 \\
\hline & $\mathrm{n}$ & 415 & 212 & 219 \\
\hline \multirow[t]{2}{*}{$49^{\text {a }}$ Franco } & Pearson & 0,810 & 0,753 & \\
\hline & $\mathrm{n}$ & 199 & 204 & \\
\hline $50^{\underline{a}} 1^{\underline{a}}$ e $2^{\underline{a}}$ & Pearson & 0,916 & & \\
\hline Sessões & $\mathrm{n}$ & 481 & & \\
\hline
\end{tabular}

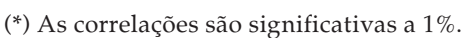

$\mathrm{n}=$ número de legisladores (incluídos) servindo em $\mathrm{T}$ e em $\mathrm{T}+\mathrm{i}, \mathrm{i}=1,2,3$.

Passemos para o teste de nossa hipótese. A hipótese nula é:

$h_{0:}$ os presidentes não têm influência na estabilidade das preferências individuais dos deputados.

É importante ressaltar que isso não significa que os presidentes não influenciam nas decisões dos deputados, mas apenas que não influenciam na estabilidade de suas preferências ao longo do tempo. A hipótese que testamos é: 
$h_{1:}$ os presidentes influenciam na estabilidade das preferências individuais dos deputados.

Temos por hipótese que a troca de presidentes desestabiliza as preferências, por causa das mudanças nos partidos e coalizões no poder. A correlação entre os períodos Franco e Collor de Mello é de espantosos 0,98 . Este número ressalta ainda mais pelo fato de a correlação entre os dois períodos da $50^{\mathrm{a}}$ legislatura, em que o único presidente foi Fernando Henrique, ser de 0,916 . Ou seja, os presidentes não alteram o mapa ideológico dos deputados: $\mathrm{h}_{0}$ não pode ser rejeitada. Nada impede que os presidentes mudem a posição do ponto médio ou a localização das políticas no espaço. O importante é perceber que a influência do presidente é consistente com o mapa ideológico das preferências.

Pereira e Mueller (2000:46-50) resumem bem como os presidentes influem no processo legislativo:

\begin{abstract}
"Do total de 805 propostas que tramitaram no Congresso brasileiro entre 1995 e 1998, 648 (80,49\%) foram iniciadas pelo Executivo, 141 $(17,51 \%)$ foram iniciadas pelo Legislativo e apenas $16(1,98 \%)$ pelo Judiciário. O tempo médio para uma proposta do Executivo ser sancionada pelo Congresso foi de 183 dias; no caso das propostas iniciadas pelo Legislativo e pelo Judiciário, este prazo estendeu-se para 1.194 e 550 dias, respectivamente." (idem:47)
\end{abstract}

Citando dados de Limongi e Figueiredo, Pereira e Mueller afirmam que o mesmo padrão se verifica entre 1989 e 1994. Das 1.259 leis aprovadas, 997 foram iniciadas pelo Executivo. Estes dados, em conjunto com outras evidências de controle da agenda pelo Executivo (Limongi e Figueiredo, 1998), atestam o papel central do Executivo na análise da Câmara dos Deputados.

Mas o que exatamente o Executivo quer? Os mapas espaciais mostram dois presidentes, Fernando Henrique e Collor de Mello, bem à direita na primeira dimensão. Tudo indica que os presidentes polarizam as decisões congressuais, tentando pressionar os membros de sua base de apoio a aprovar suas políticas. A exceção foi Itamar Franco. Se o presidente polariza a Câmara, por que Itamar Franco está no centro da primeira dimensão? 
Figura 4

Câmara dos Deputados - 49ํㅗㄴ Legislatura

\section{Governo Itamar Franco}

Pontos Ideais dos Deputados
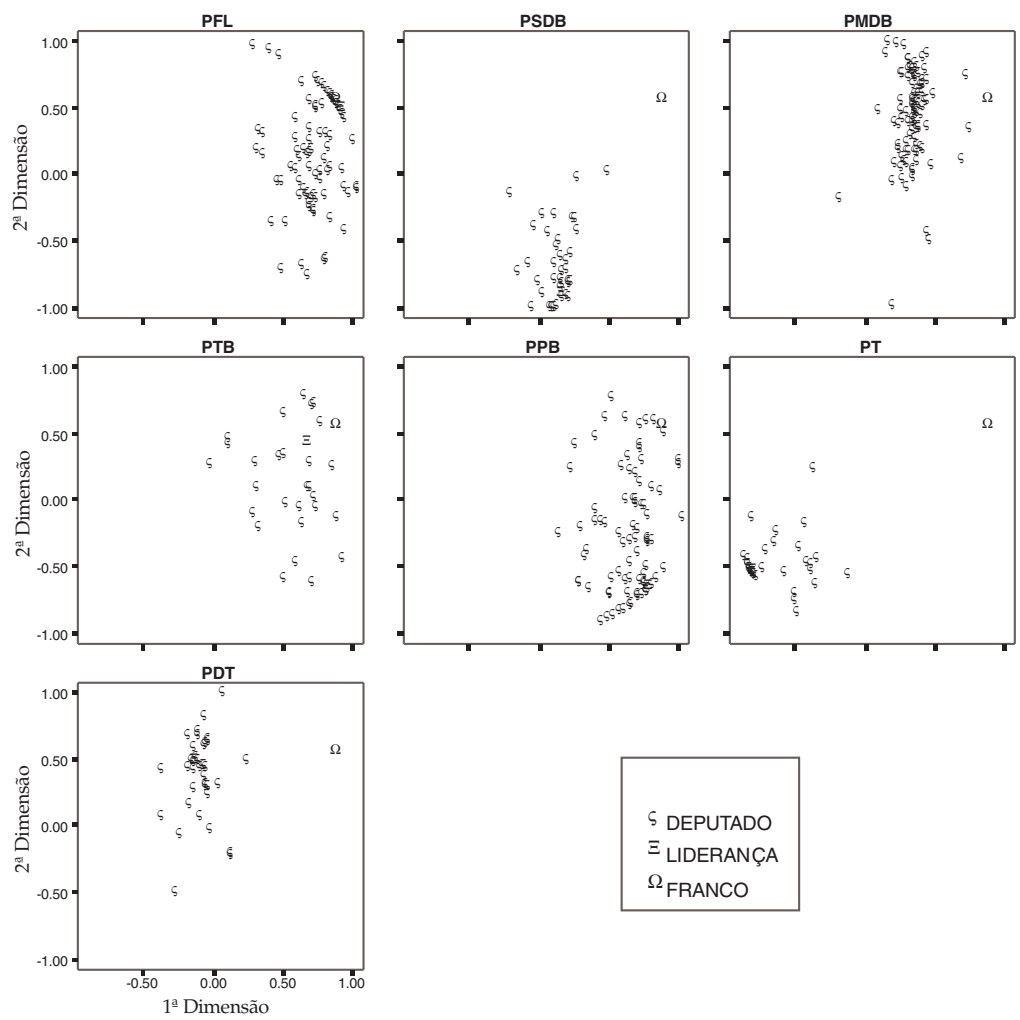

$$
\begin{aligned}
& \varsigma \text { DEPUTADO } \\
& \Xi_{\text {LIDERANÇA }} \\
& \Omega_{\text {FRANCO }}
\end{aligned}
$$

O enigma é solucionado quando fazemos em separado a análise dos votos da 49a legislatura para o período em que Franco era o presidente. A figura seguinte mostra o mapa espacial do período:

A reanálise mostra o presidente Itamar Franco na direita do espaço político, quase confundido com a indicação do líder do PFL. Ou seja, Franco só é um caso desviante se considerarmos a 49a legislatura como um todo, mas não se levarmos em conta somente seu governo. Nessa nova divisão, todos os presidentes se encontram na extrema-direita da primeira dimensão, acima do $90^{\circ}$ percentil.

Até agora, não enfrentamos uma questão fundamental na análise espacial da Câmara dos Deputados: qual, afinal, o significado da pri- 
meira dimensão? Nos Estados Unidos, os partidos políticos estruturam esta dimensão:

“Embora as dimensões sejam abstrações matemáticas, o leitor pode considerar que a primeira dimensão diferencia os fiéis ao partido dos infiéis. [Ela] parte dos muito leais a um partido, passa pelos que são pouco leais a qualquer partido, e termina nos que são muito leais a um segundo partido" (Poole e Rosenthal, 1997:230).

Substitua a palavra "partido" por "Executivo" e "Oposição" e você terá uma interpretação bastante razoável da primeira dimensão da Câmara dos Deputados brasileira. O continuum ideológico dessa dimensão pode ser entendido como indo da oposição total às propostas do Executivo ao apoio incondicional a este. Um ex-presidente da Câmara parece concordar:

"(S)e um estrangeiro visitasse hoje o Congresso ficaria com a impressão de que existem três partidos no Brasil: um que vota a favor do governo, outro que vota contra e um terceiro que vota alternadamente" (afirmação atribuída a Michel Temer, O Estado de S. Paulo, 31/12/2001).

Todos os presidentes no período estudado se posicionaram do mesmo lado da 1a dimensão. Não sabemos, ainda, o que ocorreria se um presidente "oposicionista" estivesse no poder. No entanto, essa dimensão não é refeita a cada eleição, ou seja, ela é moderadamente estável.

\section{CONCLUSÃO}

Este artigo procurou estimar as posições ideológicas dos deputados a partir das preferências expressas por eles nas votações nominais. A análise revelou uma estrutura ideológica basicamente unidimensional, que prediz corretamente mais de $85 \%$ dos votos.

A localização dos partidos nos mapas espaciais não está em conflito com a percepção usual do quadro partidário na Câmara. A vantagem óbvia é que temos não só as posições dos partidos como um todo, mas de cada membro específico, dos líderes e do Executivo. Os deputados em geral não mudam muito de posição espacial de uma legislatura para outra, ou seja, a estrutura é estável. 
O fato de todos os presidentes do período estarem localizados na extrema-direita do espectro ideológico parece sustentar a hipótese de que a primeira dimensão está fortemente relacionada com as posições adotadas pelo Executivo nas votações da Câmara dos Deputados.

Limongi e Figueiredo (1995) consideram que as posições dos líderes partidários predizem corretamente a maior parte dos resultados na Câmara dos Deputados. Eles argumentam, ainda, que os partidos se comportam ideologicamente. Neste artigo, partimos do princípio de que os deputados podem, individualmente, escolher seu posicionamento no espectro ideológico. De fato, os mapas espaciais mostram que os legisladores dispõem de grande margem de escolha, com exceção dos membros de partidos de esquerda, especialmente os do PT. A estimativa de posições individuais dos deputados, em vez de partidos, tem melhor justificativa teórica e parece representar muito bem a configuração das preferências na Câmara dos Deputados.

O modelo estatístico que utilizamos explica a maior parte das votações nominais. Portanto, nossas estimativas das preferências individuais são bastante aceitáveis, além do que elas são adequadamente representadas em uma só dimensão. Esses achados colocam as análises da Câmara dos Deputados baseadas na teoria da escolha racional em terreno mais firme. Afinal, esses modelos requerem alguma estimativa das preferências dos atores e muitas vezes partem da premissa de que o espaço político é unidimensional.

A ampla disponibilidade de medidas individuais de preferências, como o W-NOMINATE, proporcionou uma rápida expansão nos estudos empíricos sobre o Legislativo norte-americano sob a égide da teoria da escolha racional. Nossa aspiração é que um fenômeno parecido ocorra no Brasil ${ }^{5}$.

(Recebido para publicação em dezembro de 2001)

(Versão definitiva em agosto de 2002) 


\section{Eduardo Leoni}

\section{NOTAS}

1. Estes números foram extraídos do Banco de Dados CEBRAP de votações nominais na Câmara dos Deputados.

2. Remetemos o leitor interessado ao Apêndice A de Poole e Rosenthal (1997).

3. Acrescidas de "Sim" para votações de projetos introduzidos pelo governo.

4. (Número de votos corretamente classificados)/(número de votos).

5. As posições ideais dos deputados da $49^{a}$ e $50^{\text {a }}$ legislaturas estão disponíveis para download na minha página na Internet www.columbia.edu/ ell2002.

\section{REFERÊNCIAS BIBLIOGRÁFICAS}

AMES, Barry. (2001), The Deadlock of Democracy in Brazil. Ann Arbor, The University of Michigan Press.

BLACK, Duncan. (1958), The Theory of Committees and Elections. Cambridge, Cambridge University Press.

COPPEDGE, Michael. (1998), "The Dynamic Diversity of Latin American Party Systems". Party Politics, vol. 4, no 4 .

DESPOSATO, Scott W. (1998), Parties for Rent? Careerism, Ideology, and Party Switching in the Brazilian Chamber of Deputies. Manuscrito.

HINICH, Melvin e MUNGER, Michael. (1997), Analytical Politics. Cambridge, Cambridge University Press.

LIMONGI, Fernando e FIGUEIREDO, Argelina Cheibub. (1995), “Partidos Políticos na Câmara dos Deputados: 1989-1994". Dados, vol. 38, no 3, pp. 497-525.

. (1998), “Bases Institucionais do Presidencialismo de Coalizão”. Lua Nova, no 44, pp. 81-106.

MCKELVEY, Richard D. (1976), "Intransitivities in Multidimensional Voting Models and some Implications for Agenda Control". Journal of Economic Theory, 12, pp. 472-482.

PEREIRA, Carlos e MUELLER, Bernardo. (2000), “Uma Teoria da Preponderância do Poder Executivo. O Sistema de Comissões no Legislativo Brasileiro". Revista Brasileira de Ciências Sociais, vol. 15, no 43, pp. 45-67.

POOLE, Keith. (1997), “Changing Minds? Not in Congress!". Graduate School of Industrial Administration, Working Paper, 1997-22.

_ e ROSENTHAL, Howard. (1985), “A Spatial Model for Legislative Roll Call Analysis". American Journal of Political Science, vol. 29, pp. 357-384. 
. (1997), Congress: A Political-Economic History of Roll Call Voting. New York, Oxford University Press.

. (2001), “D. NOMINATE after 10 Years. A Comparative Update to Congress: A Political-Economic History of Roll Call Voting". Legislative Studies Quartely, vol. 26, pp. 5-29.

\section{ABSTRACT \\ Ideology, Democracy and Parliamentary Behavior: The Brazilian Chamber of Deputies (1991-1998)}

In this work we apply quantitative methods to recover the individual preferences of Brazilian representatives, as expressed in their nominal votes in the 49th and 50th legislatures. The method assumes both the rational choice and spatial theories of voting. Empirical analyses show that Brazilian representatives can be accurately positioned in a single ideological continuum that reflects, in part, the consensus of Brazilian politics observers: members of the Partido dos Trabalhadores (PT - Workers' Party) are positioned at the extreme left and those of the Frente Liberal (PFL - Liberal Front) at the opposite end. The Partido da Social Democracia Brasileira (PSDB - Party of the Brazilian Social Democracy), in turn, moved from a center-left position in the 49th legislature to the right, in the 50th. Additional dimensions contribute very little to the explanatory capacity of the model. The spatial positioning of representatives of a same party vary significantly, and the paramount quality of the statistical model used is its capacity to provide us with a spatial interpretation of this variation. The first dimension is rather stable in both legislatures. Circumstantial evidence is raised to support the hypothesis that these dimensions reflect the relationship between the Executive and the Legislative branches of government. During this period, the Presidents of the Republic were located at the extreme right of the political space.

Keywords: democratic Brazil; parliamentary behavior; Chamber of Deputies; nominal votes 


\section{Eduardo Leoni}

\section{RÉSUMÉ}

Idéologie, Démocratie et Comportement au Parlement: La Chambre des Députés (1991-1998)

Dans cet article, on dégage, par le moyen de méthodes quantitatives, les préférences individuelles des députés telles qu'ils les ont exprimées dans leurs votes nominaux pendant les $49^{\text {ème }}$ et $50^{\text {ème }}$ législatures brésiliennes. Cette méthode part du présupposé du choix rationnel et de la théorie de l'espace occupé par le vote. L'analyse empirique montre que les députés brésiliens peuvent être replacés avec exactitude dans un même continuum idéologique. Celui-ci reflète en partie le consensus entre les observateurs de la politique brésilienne, qui situent les membres du Parti des Travailleurs (PT) à l'extrême gauche et les membres du Parti du Front Libéral (PFL) à droite. Quant au Parti de la Social-Démocratie (PSDB), il s'est déplacé de sa position de centre gauche pendant la $49^{\text {ème }}$ législature, vers la droite pendant la $50^{\text {ème }}$. D'autres paramètres n'améliorent guère les possibilités d'explication du modèle. Il y a une variation substantielle dans la position spatiale des députés d'un même parti, la principale qualité du modèle statistique étant son aptitude à fournir une interprétation spatiale à cette variation. Le premier paramètre est assez stable entre les deux législatures. Quelques arguments sont formulés privilégiant l'hypothèse selon laquelle les paramètres reflètent les relations entre l'Exécutif et le Législatif. Les Présidents de la République de cette période se situent à l'extrême droite de l'espace politique.

Mots-clé: Brésil démocratique; comportement au parlement; Chambre de Députes; vote nominaux 